\title{
Early treatment of unstable angina in the coronary care unit: a randomised, double blind, placebo controlled comparison of recurrent ischaemia in patients treated with nifedipine or metoprolol or both
}

\author{
^REPORT OF THE HOLLAND INTERUNIVERSITY NIFEDIPINE/METOPROLOL \\ TRIAL (HINT) RESEARCH GROUP†
}

From the Netherlands Interuniversity Cardiology Institute, Utrecht, the Netherlands

SUMMARY A multicentre, double blind, placebo controlled, randomised trial of nifedipine, metoprolol, and nifedipine and metoprolol combined was conducted in a group of 338 patients with unstable angina not pretreated with a $\beta$ blocker and of nifedipine in 177 patients pretreated with a $\beta$ blocker. The main outcome event was recurrent ischaemia or myocardial infarction within 48 hours. Trial medication effects were expressed as ratios of event rates relative to placebo. In patients not pretreated with a $\beta$ blocker the event rate ratios with associated $95 \%$ confidence intervals were $1.15(0.83,1.64)$ for nifedipine, $0.76(0.49,1.16)$ for metoprolol, and $0.80(0.53$, $1 \cdot 19)$ for nifedipine and metoprolol combined. In patients already on a $\beta$ blocker the addition of nifedipine was beneficial (rate ratio $0.68(0.47,0.97)$ ). Equal numbers of patients developed myocardial infarction and reversible ischaemia. Most infarctions occurred early, within six hours of randomisation. In patients not already on a $\beta$ blocker the nifedipine rate ratio for infarction only was $1 \cdot 51(0 \cdot 87,2 \cdot 74)$.

These results suggest that in patients not on previous $\beta$ blockade metoprolol has a beneficial short term effect on unstable angina, that fixed combination with nifedipine provides no further gain, and that nifedipine may be detrimental. On the other hand, the addition of nifedipine to existing $\beta$ blockade when the patient's condition becomes unstable seems beneficial.

Requests for reprints to Prof J Lubsen, Thoraxcentre, PO Box 1738, 3000 DR Rotterdam, The Netherlands.

^Report prepared by J Lubsen, J G P Tijssen, H J J Kerkkamp.

†The Holland Interuniversity Nifedipine/metoprolol Trial Research Group is made up of the following:

Executive Committee F L Meijler (chairman), A C Arntzenius, A J Dunning, P G Hugenholtz, G A van der Kley, K I Lie, H R Michels, J P Roos, J T C Vonk, H J J Wellens, J P Zijlstra Policy Advisory Board O S Miettinen (chairman), M E Bertrand, C R Conti, D G Julian, E L Noach, A Vedin

Classification Committee J W Viersma (chairman), J M de Beyer, P J de Feyter

Coordinating Centre J Lubsen (director), J G P Tijssen (chief statistician), G Bédier de Prairie, M Bokslag, $S$ van der Does, R T van Domburg, Y M te Giffel, H J J Kerkkamp, M Smits, C J Speelman, $P$ Vrijdag

Participating Centres The cardiology departments of the following hospitals: Free University Hospital, Amsterdam (J P Roos (chief), H J J Kerkkamp, A C van Rossum, F W A Verheugt); Academic Medical Centre, Amsterdam (A J Dunning (chief), J P van Mantgem, J D Durrer); Catharina Hospital, Eindhoven (H R Michels,
J J R M Bonnier); Leyenburg Hospital, The Hague (G A van der Kley, F J de Nooyer, F Vermeer); Sint Lambertus Hospital, Helmond (J P Zijlstra, R J A F Vroom); University Hospital, Leiden (B Buis (chief), A C Arntzenius, J G Engbers, G P Molhoek, $C$ van Rees); Sint Annadal Hospital, Maastricht (H J J Wellens (chief), F W H M Bär, C de Zwaan, M Ramentol); Radboud Hospital, Nijmegen ( J T C Vonk (chief), R T van Dam, N H J Pijls); Thoraxcentre, University Hospital Rotterdam-Dijkzigt (P G Hugenholtz (chief), M L Simoons); University Hospital, Utrecht (F L Meijler (chief), E O Robles de Medina, P W Westerhof, P J P Kuijer).

Accepted for publication 14 July 1986

Patients admitted to a coronary care unit with acute chest pain present a spectrum of signs and symptoms ranging from those that are characteristic of acute myocardial infarction to chest pain without myocardial ischaemia. Within these two extremes a subgroup of patients can be identified who have signs and symptoms that are atypical of myocardial 
infarction but characteristic of myocardial ischaemia-anginal pain at rest not severe enough to suggest myocardial infarction, combined with changing electrocardiographic findings compatible with ischaemia but not directly diagnostic of infarction. This syndrome is usually called unstable angina. Patients with this diagnosis at admission to the coronary care unit may be in the process of sustaining a myocardial infarction. Alternatively, the infarction may not yet have occurred, and the patient should be considered at risk for recurrent and possibly irreversible ischaemia. ${ }^{1-3}$

After initial pain relief the aims of early treatment are the prevention of recurrent ischaemia or myocardial infarction and the restoration of a stable condition. Calcium antagonists and $\beta$ blockers are among the agents that have been advocated as being useful in this respect. ${ }^{4-8}$ Calcium antagonists are thought to increase oxygen supply by coronary vasodilation and $\beta$ blockers are assumed to reduce oxygen demand by decreasing heart rate and myocardial contractility. ${ }^{910}$ However, $\beta$ blockers have also been implicated as a potential cause of increased coronary vasomotor tone $\mathrm{e}^{1112}$ and calcium antagonists in the coronary steal phenomenon..$^{913}$ Furthermore, several cases of severe congestive heart failure have been reported in patients treated with both drugs. ${ }^{14}$ is

In 1980 the Holland Interuniversity Nifedipine/ metoprolol Trial (HINT) research group initiated a randomised, double blind, placebo controlled, multicentre trial to assess the role of calcium antagonists and $\beta$ blockers in the treatment of unstable angina. At that time this role had not been defined. ${ }^{16}$ The objective of the trial was to determine whether nifedipine (a calcium antagonist) and metoprolol (a $\beta$ blocker) could prevent recurrence of ischaemia or progression to myocardial infarction when given either alone or in combination to patients diagnosed as having unstable angina at admission to the coronary care unit. The trial was confined primarily to an observation period of $\mathbf{4 8}$ hours, although long term follow up continues. The protocol was designed to follow established cardiological practice as closely as possible. In particular, patients were admitted to the trial as soon as unstable angina was suspected before myocardial infarction could be excluded by enzyme measurements.

The trial was carried out under the auspices of the Interuniversity Cardiology Institute, in which all academic cardiology departments in the Netherlands participate. The trial was funded by the Dutch Ministry of Education. In addition, it was supported by grants from Bayer GmbH, Wuppertal, Germany, and Hässle AB, Mölndal, Sweden.

The first patient was enrolled on 1 February 1981.
On 30 October 1984 enrolment was discontinued because an interim analysis suggested that the risk of myocardial infarction was higher in patients assigned to nifedipine than in patients treated with the other trial medications. The data on which this decision was based are reproduced in appendix I. Both Bayer and Hässle and the Dutch health authorities were informed of the decision but not of the actual data. This report deals with the main findings on the efficacy of nifedipine and metoprolol in preventing recurrent ischaemia and myocardial infarction in the 515 patients who were eventually available for analysis.

\section{Patients and methods}

\section{ORGANISATION}

Eight university and three non-university cardiology departments participated. Before the start of the trial the protocol was approved by the Scientific Council of the Interuniversity Cardiology Institute and by the principal investigators of participating nonuniversity hospitals (together they formed the Executive Committee) and by the ethics committees at each participating centre. A Policy Advisory Board of acknowledged experts in related fields, not otherwise associated with the trial, also approved the protocol and adopted the task of progress monitoring. Until the decision was taken to discontinue the trial only this board was informed of the interim results.

Data were processed by the Clinical Epidemiology Unit of the Thoraxcentre in Rotterdam, which also provided overall coordination. Its staff was kept unaware of the patient medication assigned and interim results until the trial was discontinued.

The clinical course, electrocardiograms, and laboratory data of each patient up to 48 hours after start of trial medication were reviewed by a committee of three experienced cardiologists. This Classification Committee, which was unaware of the trial medication assignment and findings at subsequent angiography, determined which clinical events had taken place up to $\mathbf{4 8}$ hours after randomisation, according to predefined guidelines.

\section{PATIENT RECRUITMENT AND INCLUSION} CRITERIA

At admission to hospital patients were screened for immediate inclusion before the results of the enzyme measurements were known. Chest pain (if present) was treated with sublingual glyceryl trinitrate (maximum two $0.5 \mathrm{mg}$ doses) and if it persisted an intravenous injection of glyceryl trinitrate (maximum 1 $\mathrm{mg}$ in $10 \mathrm{ml} 5 \%$ glucose) or fentanyl $(0.05 \mathrm{mg})$ was given.

To qualify for admission to the trial the presence of either of the following was required: a chest pain 
episode in the hospital accompanied by a varying pattern of ST-T changes suggesting reversible myocardial ischaemia; a history of typical angina at rest or during light activity occurring within 12 hours of admission and lasting $>15 \mathrm{~min}$ combined with either ST-T abnormalities, a documented history of myocardial infarction or unstable angina, or at least $50 \%$ narrowing of a major coronary artery observed at earlier angiography. Patients who did not qualify at hospital admission were included on the basis of the above criteria when chest pain subsequently developed, provided that available enzyme values were below twice the local upper limit for normal.

If pain could not be relieved as described above, the patient was not admitted to the trial. In addition, the following exclusions were applied: age $>70$, new $Q$ wave formation on the electrocardiogram, acute myocardial infarction within one week, maintenance treatment with nifedipine, heart rate below 50 or above 120 beats/minute, systolic blood pressure < $100 \mathrm{~mm} \mathrm{Hg}$, systolic blood pressure $>170 \mathrm{~mm} \mathrm{Hg}$ and diastolic pressure $>110 \mathrm{~mm} \mathrm{Hg}$, conduction abnormalities other than bundle branch block, anaemia (haemoglobin $<6.5 \mathrm{mmol} / \mathrm{l}$, if known), clinically overt heart failure, congenital or valvar heart disease, cardiomyopathy, serious pulmonary or other non-cardiac disease, and previous participation in this trial. After eligibility had been established, oral informed consent was asked for and if it was obtained the trial medication was started without further delay.

\section{TREATMENT}

All patients received routine care for at least 48 hours. Sedatives and anticoagulants were given according to local practice. Oral long acting nitrates were continued if they had been given before admission to hospital; otherwise these drugs were not part of the standard regimen. Antiarrhythmics, digitalis, diuretics, and antihypertensive agents other than $\beta$ blockers were given on indication only. Previous maintenance treatment with a $\beta$ blocker was continued; before 13 November 1982 with the same compound and dose as given before, thereafter with two $100 \mathrm{mg}$ doses of metoprolol per 24 hours. Chest pain was initially treated as described above. If pain persisted the decision to use further measures was left to the discretion of the attending physician.

Trial medication was added to the standard regimen as follows. Patients not on previous maintenance treatment with a $\beta$ blocker for $>3$ days were randomly assigned to receive either double placebo, nifedipine six $10 \mathrm{mg}$ doses per 24 hours plus metoprolol placebo, metoprolol two $100 \mathrm{mg}$ doses per 24 hours plus nifedipine placebo, or both drugs. Patients on previous maintenance treatment with a $\beta$ blocker were randomly assigned to receive placebo or nifedipine six doses of $10 \mathrm{mg}$ per 24 hours. No loading dosages were given. Both nifedipine and metoprolol (or their placebos) were started at the same time. Both randomisation procedures were performed for each clinic separately and in equal proportions.

Unless persistent chest pain developed, the trial medication was continued for at least $\mathbf{4 8}$ hours, preferably until catheterisation or discharge. In the event of suspected side effects trial medication was reduced or discontinued. The treatment code could be broken but only if it was considered mandatory by the attending physician. For this purpose a coding envelope was packed with each package of the trial medication.

\section{DATA COLLECTION AND FOLLOW UP}

Twelve lead electrocardiograms were recorded every six hours as well as during and after episodes of chest pain over the period from hospital admission until 48 hours after start of trial medication. The extent of ST depression and elevation was coded as described in appendix II in two electrocardiograms recorded before start of trial medication-that is, the last electrocardiogram obtained in the absence of pain (the baseline electrocardiogram) and for patients with pain while in hospital an electrocardiogram made during pain (the pain electrocardiogram).

Blood samples for measurement of activities of creatine kinase or its isoenzymes or both were obtained at least once before start of trial medication and every six hours until $\mathbf{5 4}$ hours thereafter. The activities of glutamic oxaloacetic and pyruvic transaminases, lactic acid dehydrogenase, and $\alpha$ hydroxybutyric acid dehydrogenase were determined every 24 hours. After 54 hours enzyme measurements were left to local routine but were recorded when available. All enzyme determinations were performed locally and were subsequently related to local normal values. Heart rate was recorded every hour and blood pressure every six hours.

Cardiac catheterisation and coronary angiography, unless contraindicated, were performed preferably before discharge but not within 54 hours after start of trial medication.

\section{DEFINITION OF OUTCOME EVENTS AND DATA}

ANALYSIS

A patient was classified as having "pre-randomisation myocardial infarction" when concentrations of one or more cardiac enzymes measured before the start of trial medication were significantly raisedthat is, to more than twice the local upper limit for normal. In this case no outcome classification was defined. For all other patients the following two out- 
come events were defined: recurrent ischaemia or myocardial infarction within 48 hours-that is, chest pain with ST-T changes and/or enzymatic evidence of infarction as defined below; myocardial infarction within 48 hours-that is, cardiac death or characteristic serial enzyme pattern with at least one cardiac enzyme significantly raised within $\mathbf{5 4}$ hours (as there is an intrinsic delay in the release of enzymes after the onset of myocardial infarction enzyme values until 54 hours after randomisation were taken into account). Myocardial infarction which occurred within the remainder of the first seven days was recorded according to clinical diagnosis. For all cases classified as myocardial infarction within $\mathbf{4 8}$ hours the most likely time of onset was determined retrospectively from the complete clinical history. In addition, the time of appearance of a $Q$ wave lasting $>0.03$ seconds or of a $Q$ wave equivalent $(R>0.03$ seconds in V1 and R/S > 1 in V2) was noted.

Those patients for whom an unequivocal protocol violation occurred before the start of trial medication were excluded from analysis. These exclusions were applied retrospectively by the Classification Committee. Patients were retained, however, if the committee disagreed with the attending physician's assessment of qualifying ST-T abnormalities or changes. Treatment effects were assessed in terms of the occurrence of the two outcome events defined above. In accordance with the protocol, patients classified as having pre-randomisation myocardial infarction were excluded from this assessment. Treatment effects were expressed as the ratio of the rate of the respective outcome event observed in patients allocated to a specific index trial medication to that observed in patients allocated to a specific reference trial medication. For instance, the effect of nifedipine relative to placebo is the rate of the outcome event in the nifedipine group divided by that in the placebo group. Thus a rate ratio of one indicates that nifedipine has no effect relative to placebo. A rate ratio of $<1$ points to a preventive effect and a rate ratio $>1$ to a detrimental effect. The $95 \%$ confidence intervals of the rate ratio estimates are also given.

We used a composite logistic prediction function to determine which baseline characteristics were independently related to the risk of recurrent ischaemia or myocardial infarction within $\mathbf{4 8}$ hours. The baseline risk of recurrent ischaemia or myocardial infarction within $\mathbf{4 8}$ hours (that is, the probability that such an event would occur) was estimated for each patient separately given individual baseline characteristics and the prediction function. Patients were subsequently divided into three subgroups of low, medium, and high risk.

In the analysis we found that despite random allocation, trial medication groups differed in terms of the distribution of baseline risk. To adjust for this, relative treatment effects, as defined above, were estimated as weighted averages of risk subgroup specific effects. Full details of the analytic methods are given in appendix II.

\section{STUDY SIZE REQUIREMENTS}

The protocol stated that trial treatments were to be evaluated in terms of the rates of recurrent ischaemia or myocardial infarction within 48 hours in patients without myocardial infarction at the start of trial medication. If it is assumed that this rate would be $40 \%$ in placebo treated patients who were not already on $\beta$ blockade, that nifedipine and metoprolol alone would reduce this rate to $20 \%$, and that the combination would reduce this further to $10 \%$ (that is event rates of $40 \%, 20 \%, 20 \%$, and $10 \%$ respectively), 70 patients per group are required for a $97 \%$ chance of obtaining a statistically significant $(p<0.05)$ result in a $4 \times 2$ continguency table $\chi^{2}$ test. ${ }^{17}$ To allow for lower rates and the possibility that only the combination would be effective, we planned to study 150 patients per group.

\section{Kesults}

\section{RECRUITMENT AND EXCLUSIONS}

Between 1 February 1981 and 30 October 1984, 668 patients were enrolled. The median contribution per centre was 50 patients, ranging from seven (for a centre that participated only during the last nine months) to 144. Randomisation by centre resulted in balanced trial medication groups.

Figure 1 shows that a violation of the admission protocol occurred in 131 patients; these cases were excluded. Another 22 patients classified as having pre-randomisation myocardial infarction were left out from trial medication assessment. In $82 \%$ of the 515 remaining patients the treating physician's judgement on qualifying ST-T abnormalities or changes was independently confirmed by the Classification Committee. Figure 1 also shows the overall occurrence of relevant clinical events. All deaths were caused by myocardial infarction.

Figure 2 shows the time of onset in 89 cases of non-fatal myocardial infarction within 48 hours of the start of trial medication. In 43 patients acute myocardial infarction was thought to have occurred before the start of trial medication despite cardiac enzyme concentrations being below twice the upper limit for normal at that time. Figure 2 also shows the time of first occurrence of a significant rise in enzyme concentrations and that of a new $Q$ wave.

Table 1 shows selected baseline characteristics in 


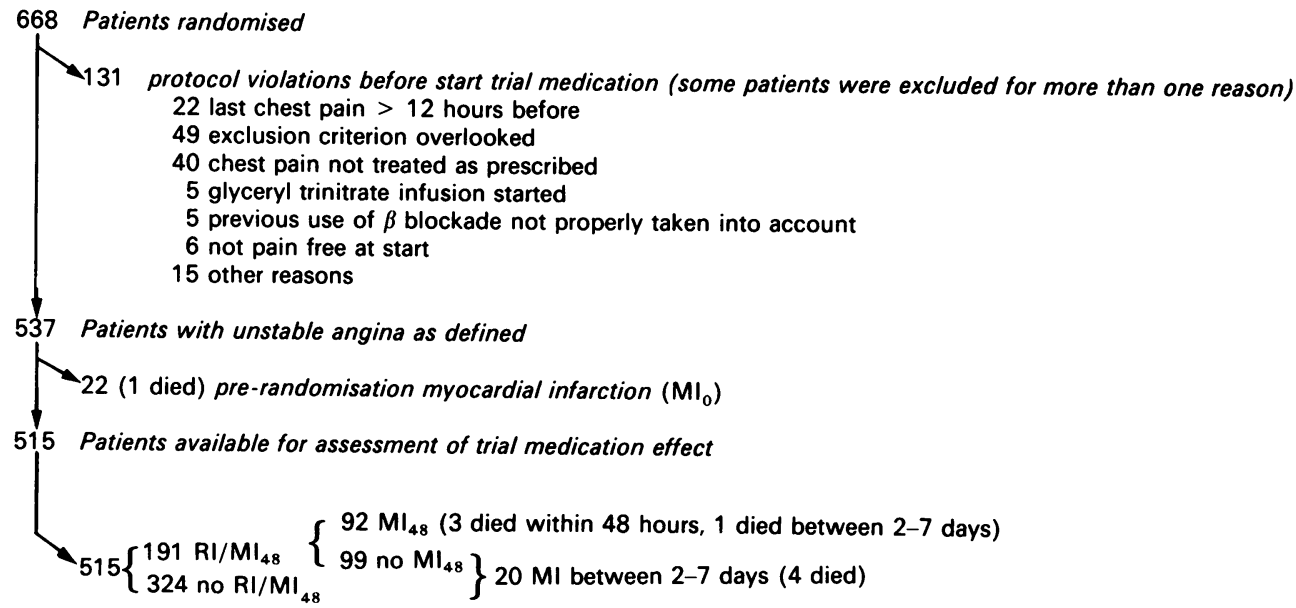

Fig 1 Exclusions from data analysis and overall distributions of outcome events. $M I_{0}$, pre-randomisation myocardial infarction; $R I / M I_{48}$, recurrent ischaemia or myocardial infarction within 48 hours; $M I_{48}$, myocardial infarction within 48 hours.

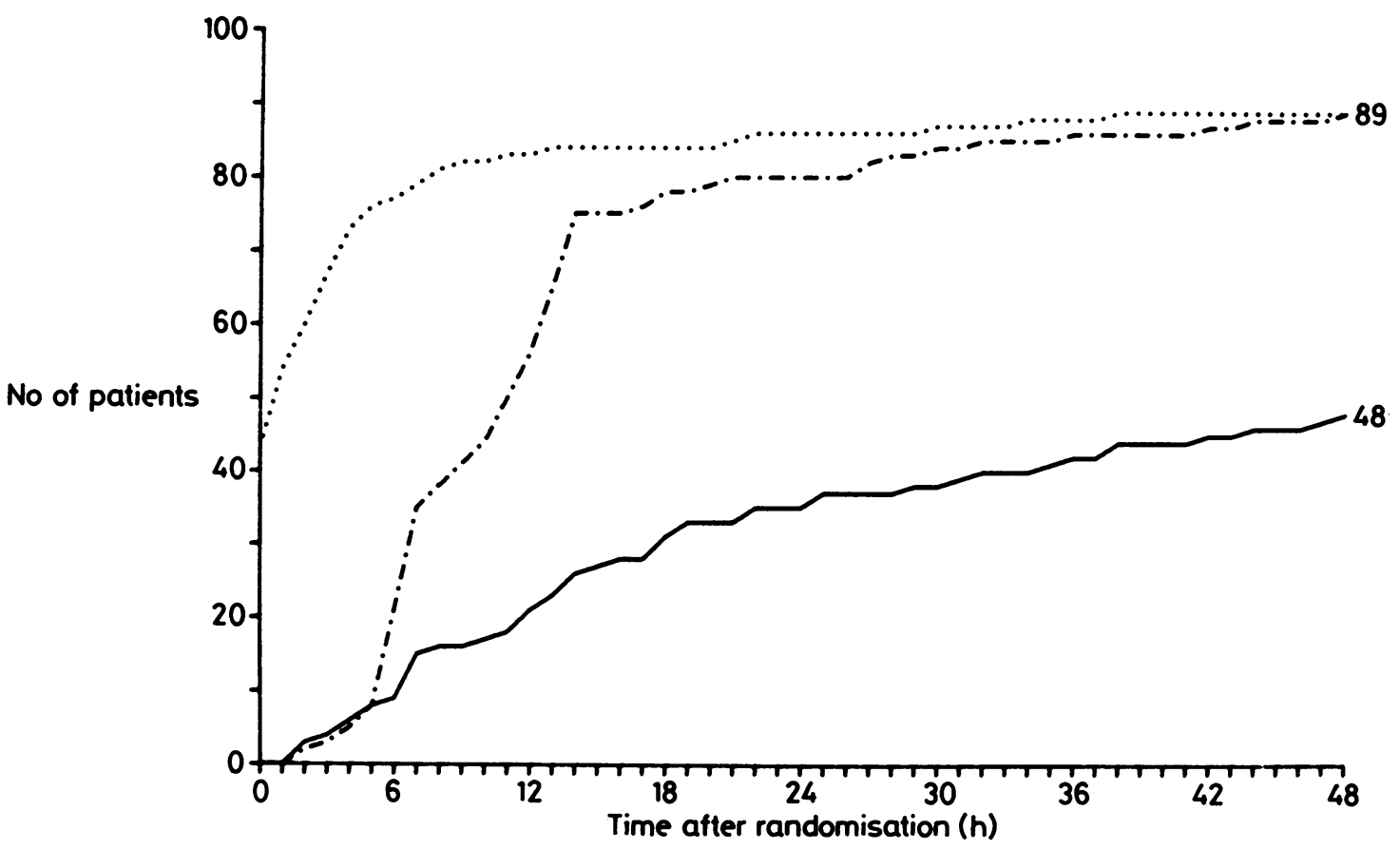

Fig 2 Timing of the onset of non-fatal myocardial infarction, the first significant rise in enzyme concentration, and the appearance of $Q$ waves for 89 cases of non-fatal myocardial infarction within 48 hours in 515 patients without enzymatic evidence of infarction at randomisation. The time of the onset of myocardial infarction was determined retrospectively by the Classification Committee from the complete clinical history. The upper dotted line represents the cumulative distribution of the time of onset of myocardial infarction-that is, it represents for each point in time after randomisation the total number of patients with an onset before that time. In 43 cases the onset was judged to have taken place before randomisation; the upper line thus starts at 43. Similarly the middle broken line represents the cumulative distribution of the time of first rise in enzyme concentration to over twice the local upper limit of normal and the lower solid line the time of first appearance of a $Q$ wave on the electrocardiogram. 
Table 1 Baseline characteristics and corresponding outcome event rates

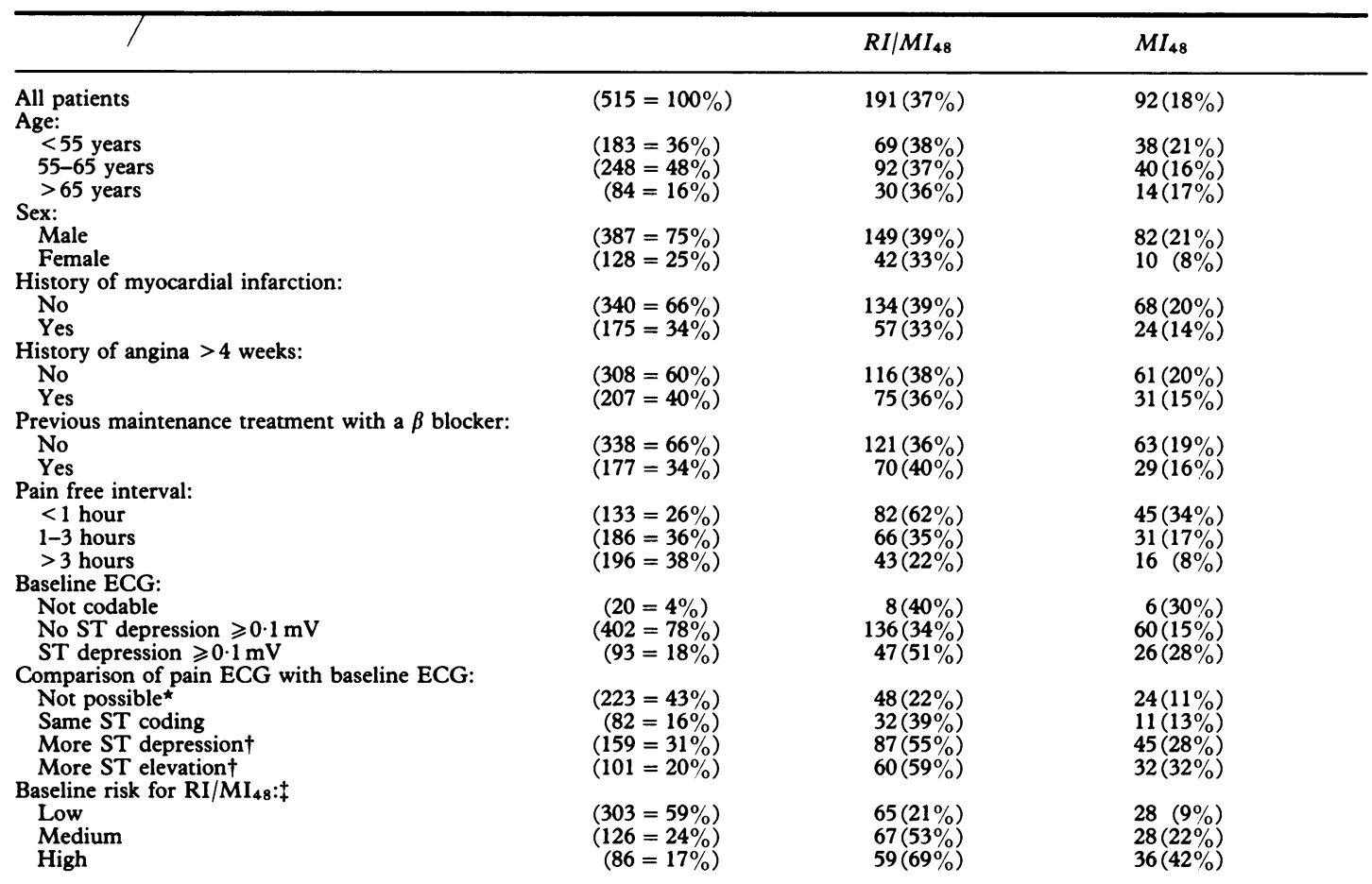

$\mathrm{RI} / \mathrm{MI}_{48}$, recurrent ischaemia or myocardial infarction within 48 hours; $\mathrm{MI}_{48}$, myocardial infarction within 48 hours; ECG, electrocardiogram.

^No pain observed after hospital admission or no (codable) pain free electrocardiogram available for comparison.

+Including 50 patients who had more ST depression as well as more ST elevation.

†As estimated from previous maintenance treatment with a $\beta$ blocker, pain free interval, baseline electrocardiogram, and comparison of pain electrocardiogram with baseline electrocardiogram (see appendix II).

relation to the defined outcome events. There were only small differences between the rates of recurrent ischaemia or myocardial infarction within 48 hours of the start of trial medication for respective categories of age, sex, history of coronary disease, and previous $\beta$ blockade. Trial medication was started after a pain free interval of less than one hour in $26 \%$ of patients and in a further $36 \%$ after an interval of between one and three hours. The length of this interval was strongly related to the rate of recurrent ischaemia or myocardial infarction within $\mathbf{4 8}$ hours: $62 \%$ of patients who had a pain free interval of less than one hour developed recurrent ischaemia or myocardial infarction within $\mathbf{4 8}$ hours as opposed to $22 \%$ of those in whom the pain free interval lasted more than three hours (table 1). The rate of recurrent ischaemia and myocardial infarction within 48 hours was also related to the presence of ST depressions $>0.1 \mathrm{mV}$ on the baseline electrocardiogram. Patients without pain observed while in hospital had a lower event rate than those with pain. In those with pain the event rate was also related to the presence of changes in ST coding during pain.
Of the baseline characteristics listed in table 1 , previous use of $\beta$ blockers, pain free interval before the start of trial medication, and ST coding of electrocardiograms made during and after pain were retained in the logistic function for the estimation of the baseline risk for recurrent ischaemia or myocardial infarction within 48 hours. Based on this estimation, $59 \%$ of patients were grouped as "low", $24 \%$ as "medium", and $17 \%$ as "high" risk. The observed rates were $21 \%, 53 \%$ and $69 \%$ respectively. The rate of myocardial infarction within 48 hours was also strongly related to this stratification. Appendix II gives full details of the logistic function.

\section{COMPARABILITY OF TRIAL MEDICATION GROUPS AND USE OF CONCOMITANT MEDICATION}

Table 2 shows the trial medication allocation. Of 338 patients who were not on previous maintenance treatment with a $\beta$ blocker 84 were assigned to placebo, 89 to nifedipine, 79 to metoprolol, and 86 to the combination. Placebo was added to continued $\beta$ 
Table 2 Distribution of baseline characteristics between trial medication groups

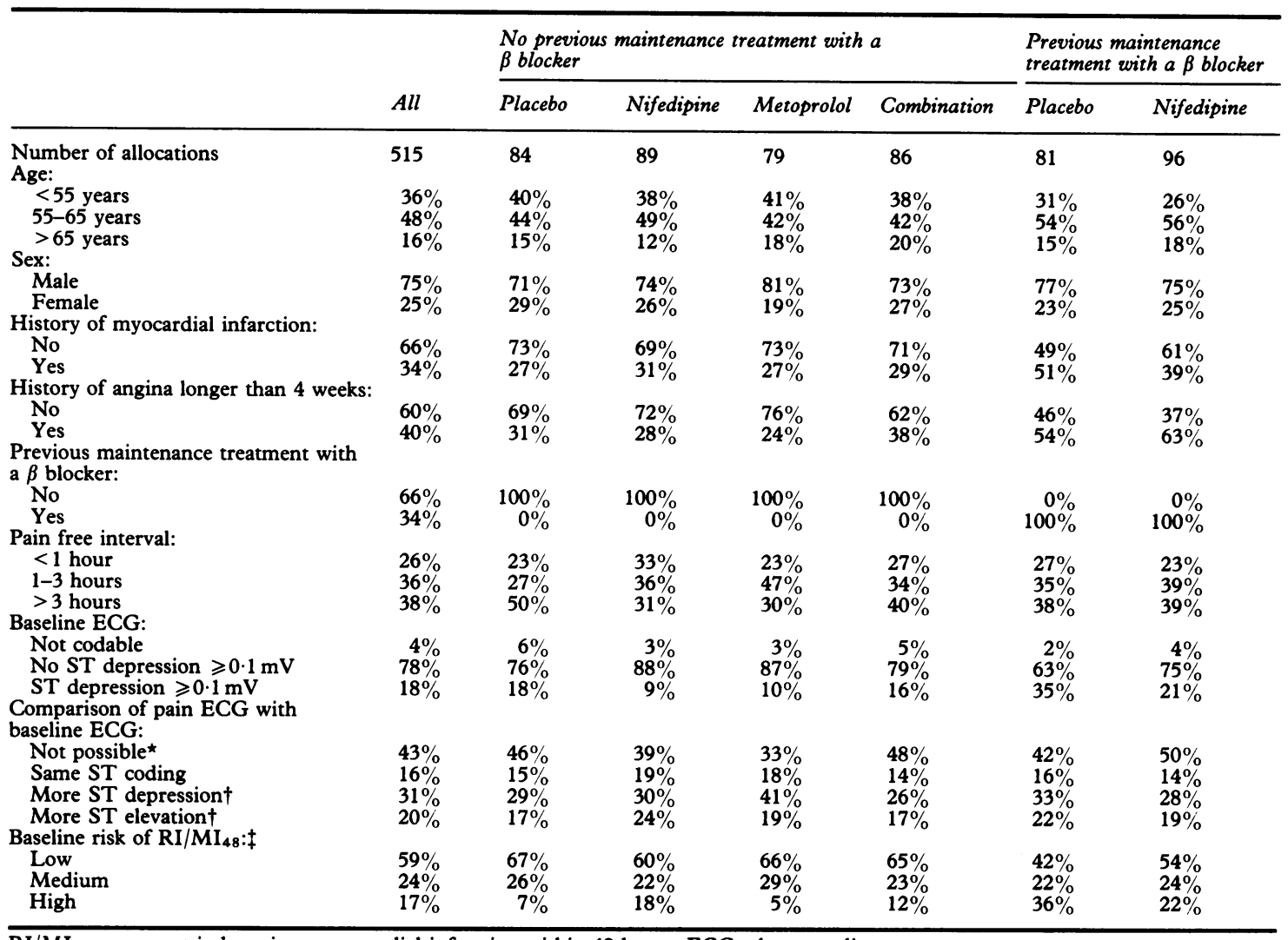

$\mathrm{RI} / \mathrm{MI}_{48}$, recurrent ischaemia or myocardial infarction within 48 hours; ECG, electrocardiogram

*No pain observed after hospital admission or no (codable) pain free electrocardiogram available for comparison.

tIncluding 50 patients who had greater ST depression and greater ST elevation.

† As estimated from previous maintenance treatment with $\beta$ blocker, pain free interval, baseline electrocardiogram, and comparison of pain electrocardiogram with baseline electrocardiogram (see appendix II).

blocker treatment in 81 patients and nifedipine in 96. Table 2 also shows the baseline characteristics for each trial medication group separately. Baseline risk for recurrent ischaemia or myocardial infarction within 48 hours was distributed differently over the trial medication groups. Among patients not on previous maintenance treatment with a $\beta$ blocker $18 \%$ of those allocated to nifedipine were high risk; for the other three trial medication groups this percentage ranged from $5 \%$ to $12 \%$. The higher risk of the nifedipine group was due primarily to a relatively large proportion $(33 \%)$ of patients in whom trial medication was started within one hour after the last attack of pain (a strong indicator of risk, table 1). In

Table 3 Use of trial medication at randomisation and during follow up for each trial medication group

\begin{tabular}{|c|c|c|c|c|c|}
\hline & & \multicolumn{4}{|c|}{ Use in relation to randomisation } \\
\hline & & At randomisation & $+6 h$ & $+24 h$ & $+48 h$ \\
\hline $\begin{array}{l}\text { Placebo } \\
\text { Nifedipine } \\
\text { Metoprolol } \\
\text { Combination }\end{array}$ & \multicolumn{5}{|c|}{$\begin{array}{lcccc}\text { No previous maintenance treatment with a } \beta \text { blocker } & & \\
(\mathrm{n}=84) & 100 \% & 94 \% & 86 \% & 76 \% \\
(\mathrm{n}=89) & 100 \% & 87 \% & 71 \% & 63 \% \\
(\mathrm{n}=79) & 100 \% & 99 \% & 82 \% & 73 \% \\
(\mathrm{n}=86) & 100 \% & 94 \% & 80 \% & 70 \%\end{array}$} \\
\hline $\begin{array}{l}\text { Placebo } \\
\text { Nifedipine }\end{array}$ & $\begin{array}{l}\text { On continued } \\
(\mathbf{n}=\mathbf{8 1}) \\
(\mathbf{n}=96)\end{array}$ & $\begin{array}{l}\text { maintenance treatmen } \\
100 \% \\
100 \%\end{array}$ & $\begin{array}{l}\text { with a } \beta \text { blocker } \\
89 \% \\
92 \%\end{array}$ & $\begin{array}{l}70 \% \\
80 \%\end{array}$ & $\begin{array}{l}65 \% \\
74 \%\end{array}$ \\
\hline
\end{tabular}


Table 4 Outcome event rates in trial medication groups stratified for estimated baseline risk for recurrent ischaemia or myocardial infarction within 48 hours

\begin{tabular}{|c|c|c|c|c|c|}
\hline & $M I_{0}$ & No $M I_{0}$ & $R I / M I_{48}$ & $M I_{48}$ & $M I_{48}+Q$ \\
\hline \multicolumn{6}{|c|}{ No previous maintenance treatment with a $\beta$ blocker } \\
\hline $\begin{array}{l}\text { Placebo: } \\
\text { All patients } \\
\text { Low risk } \\
\text { Medium risk } \\
\text { High risk } \\
\text { Nifedinipe. }\end{array}$ & 3 & $\begin{array}{r}84 \\
56 \\
22 \\
6\end{array}$ & $\begin{array}{c}31(37 \%) \\
13(23 \%) \\
13(59 \%) \\
5(83 \%)\end{array}$ & $\begin{array}{c}13(15 \%) \\
3(5 \%) \\
8(36 \%) \\
2(33 \%)\end{array}$ & $\begin{array}{l}9(11 \%) \\
2(4 \%) \\
6(27 \%) \\
1(17 \%)\end{array}$ \\
\hline $\begin{array}{l}\text { Nifedipine: } \\
\text { All patients } \\
\text { Low risk } \\
\text { Medium risk } \\
\text { High risk }\end{array}$ & 4 & $\begin{array}{l}89 \\
53 \\
20 \\
16\end{array}$ & $\begin{array}{l}42(47 \%) \\
15(28 \%) \\
14(70 \%) \\
13(81 \%)\end{array}$ & $\begin{array}{r}25(28 \%) \\
8(15 \%) \\
6(30 \%) \\
11(69 \%)\end{array}$ & $\begin{array}{c}14(16 \%) \\
4(8 \%) \\
4(20 \%) \\
6(38 \%)\end{array}$ \\
\hline $\begin{array}{l}\text { Metoprolol: } \\
\text { All patients } \\
\text { Low risk } \\
\text { Medium risk } \\
\text { High risk }\end{array}$ & 4 & $\begin{array}{r}79 \\
52 \\
23 \\
4\end{array}$ & $\begin{array}{r}22(28 \%) \\
10(19 \%) \\
9(39 \%) \\
3(75 \%)\end{array}$ & $\begin{array}{r}13(16 \%) \\
6(12 \%) \\
5(22 \%) \\
2(50 \%)\end{array}$ & $\begin{array}{l}6(8 \%) \\
2(4 \%) \\
3(13 \%) \\
1(25 \%)\end{array}$ \\
\hline $\begin{array}{l}\text { Combination: } \\
\text { All patients } \\
\text { Low risk } \\
\text { Medium risk } \\
\text { High risk }\end{array}$ & 7 & $\begin{array}{l}86 \\
56 \\
20 \\
10\end{array}$ & $\begin{array}{r}26(30 \%) \\
9(16 \%) \\
12(60 \%) \\
5(50 \%)\end{array}$ & $\begin{array}{c}12(14 \%) \\
4(7 \%) \\
5(25 \%) \\
3(30 \%)\end{array}$ & $\begin{array}{l}7(8 \%) \\
3(5 \%) \\
2(10 \%) \\
2(20 \%)\end{array}$ \\
\hline \multicolumn{6}{|c|}{ On continued maintenance treatment with a $\beta$ blocker } \\
\hline $\begin{array}{l}\text { Placebo: } \\
\text { All patients } \\
\text { Low risk } \\
\text { Medium risk } \\
\text { High risk } \\
\text { Nifedinine. }\end{array}$ & 2 & $\begin{array}{l}81 \\
34 \\
18 \\
29\end{array}$ & $\begin{array}{r}41(51 \%) \\
8(24 \%) \\
12(67 \%) \\
21(72 \%)\end{array}$ & $\begin{array}{c}16(20 \%) \\
3(9 \%) \\
2(11 \%) \\
11(38 \%)\end{array}$ & $\begin{array}{l}6(7 \%) \\
2(6 \%) \\
0(0 \%) \\
4(14 \%)\end{array}$ \\
\hline $\begin{array}{l}\text { Nifedipine: } \\
\text { All patients } \\
\text { Low risk } \\
\text { Medium risk } \\
\text { High risk }\end{array}$ & 2 & $\begin{array}{l}96 \\
52 \\
23 \\
21\end{array}$ & $\begin{array}{r}29(30 \%) \\
10(19 \%) \\
7(30 \%) \\
12(57 \%)\end{array}$ & $\begin{array}{c}13(14 \%) \\
4(8 \%) \\
2(9 \%) \\
7(33 \%)\end{array}$ & $\begin{array}{l}6(6 \%) \\
0(0 \%) \\
2(9 \%) \\
4(19 \%)\end{array}$ \\
\hline
\end{tabular}

$\mathrm{MI}_{0}$, pre-randomisation myocardial infarction; $\mathrm{RI} / \mathrm{MI}_{48}$, recurrent ischaemia or myocardial infarction within 48 hours; $\mathrm{MI}_{48}, \mathrm{myocardial}$ infarction within 48 hours; $M_{48}+Q$, myocardial infarction within 48 hours with subsequent $Q$ wave formation.

patients who were on continued $\beta$ blockade the same was true for patients allocated to placebo, although to a lesser extent.

Oral long acting nitrates had been given to 100 patients at admission to hospital and were continued in $76 \%$. Thus 439 patients did not receive oral long acting nitrates at randomisation. These drugs were later given, on indication, to $11 \%$ of these patients. Anticoagulants (coumarins or heparin) were given to $67 \%$. At the start of the trial or during follow up $14 \%$ received diuretics, $3 \%$ digitalis, and 3\% platelet aggregation inhibiting drugs. Medication at hospital admission was not related to the risk of recurrent ischaemia or myocardial infarction within 48 hours.

Table 3 shows the percentage of patients still on trial medication 6,12 , and 48 hours after randomisation. At $\mathbf{4 8}$ hours the percentage of patients still on trial medication ranged from $63 \%$ of patients allocated to nifedipine who were not on previous maintenance $\beta$ blockade to $76 \%$ of patients allocated to placebo who were not on previous $\beta$ blockade. The predominant reasons for discontinuation of trial medication were recurrent chest pain and diagnostic findings of myocardial infarction. In five patients the trial medication code was broken within 48 hours of randomisation.

OUTCOME EVENT RATES IN TRIAL MEDICATION GROUPS AND RELATIVE EFFECTS OF TREATMENT

Table 4 shows the number of pre-randomisation infarctions by trial medication group. Also shown are the outcome event rates for patients without prerandomisation infarction, both overall and according to stratum of baseline risk for recurrent ischaemia or myocardial infarction within 48 hours. The directions of the differences between the trial medication groups were consistent over the risk strata. In patients not on previous maintenance treatment with a $\beta$ blocker who were treated with nifedipine both event rates were higher than the corresponding ones for those on placebo. This was also true for $Q$ wave infarctions. On the other hand, in patients on metoprolol or on the combination, event rates tended to te lower than the rates for those on placebo. In patients who were already on a $\beta$ blocker, the nifedipine group tended to have lower event rates than the placebo group.

Table 5 gives the estimated relative effects 
Table 5 Rate ratios with $95 \%$ confidence intervals for all trial medication comparisons

\begin{tabular}{|c|c|c|}
\hline & \multicolumn{2}{|c|}{ Adjusted rate ratio ( $95 \%$ confidence interval) } \\
\hline & $R I / M I_{48}$ & $M I_{48}$ \\
\hline $\begin{array}{l}\text { Nifedipine/placebo } \\
\text { Metoprolol/placebo } \\
\text { Combination/placebo } \\
\text { Metoprolol/nifedipine } \\
\text { Combination/nifedipine } \\
\text { Combination/metoprolol }\end{array}$ & $\begin{array}{r}\text { No previous maintenance treatmer } \\
1.15(0.83,1.64) \\
0.76(0.49,1.16) \\
0.80(0.53,1.19) \\
0.66(0.43,0.98) \\
0.68(0.47,0.97) \\
1.06(0.67,1.70)\end{array}$ & $\begin{array}{l}1.51(0.87,2.74) \\
1.07(0.54,2.09) \\
0.88(0.44,1.74) \\
0.74(0.40,1.31) \\
0.56(0.30,0.99) \\
0.79(0.39,1.62)\end{array}$ \\
\hline \multicolumn{3}{|c|}{ On continued maintenance treatment with a $\beta$ blocker } \\
\hline
\end{tabular}

$\mathrm{RI} / \mathrm{MI}_{48}$, recurrent ischaemia or myocardial infarction within 48 hours; $\mathrm{MI}_{48}$, myocardial infarction within 48 hours.

expressed as weighted averages of risk stratum specific rate ratios together with the $95 \%$ confidence intervals for all choices of index and reference trial medication.

\section{Discussion}

\section{CLINICAL SPECTRUM OF UNSTABLE ANGINA DIAGNOSED AT ADMISSION TO CORONARY CARE UNIT}

According to one widely accepted definition patients who have recent onset (effort) angina, worsening angina, or angina at rest are classified as having unstable angina provided there are no signs of acute myocardial infarction. ${ }^{18}$ It is generally recognised that the differential diagnosis of such cases may be difficult and that myocardial infarction may have already occurred or may be about to occur. The present trial reports clinical events and their timing in 537 patients in whom unstable angina was diagnosed at admission to the coronary care unit.

This diagnosis was based on a combination of findings-angina at rest, evidence for causal myocardial ischaemia, and absence of signs of acute myocardial infarction such as persistent pain or characteristic electrocardiographic signs (a subcategory of unstable angina as defined above). Not unexpectedly in $4 \%$ ( 22 out of 537, fig 1 ) there had already been myocardial infarction with an increase in enzyme concentrations. These cases of myocardial infarction could have been diagnosed immediately had laboratory measurements been immediately available. Within a week of the start of the trial myocardial infarction had occurred in $25 \%(22+92+20$ out of 537, fig 1). Thus there is a considerable risk of myocardial infarction during this period. Similar percentages have been reported before ${ }^{1}$ but the time of the onset of infarction (retrospectively determined from the complete clinical history) relative to the time when the diagnosis of unstable angina was made was not given. Figure 2 shows that the onset of myocardial infarction was judged to have occurred before the start of trial medication in $\mathbf{4 3}$ cases and that there were 34 further cases within six hours of the start of the trial. Only few infarctions occurred later than six hours after the start of the trial. Thus so far as myocardial infarction occurs in patients diagnosed as having unstable angina, its onset tends to cluster around the time of diagnosis. The clinical implications of this finding are considerable and it shows that treatment which aims at the prevention of progression to myocardial infarction will have a limited effect because in most cases it will come too late.

Despite the high frequency of myocardial infarction, this trial supports the notion that the prognosis in patients with this type of unstable angina is good. Total one week mortality was only $1.7 \%$ (9/537, fig 1$)$. Our results indicate that the short term risk of recurrent ischaemia or myocardial infarction is primarily related to the interval since the last attack of pain on the one hand and to the presence of resting ST abnormalities and pain related ST changes on the other (table 1 and appendix II). The first finding is understandable because by definition the condition of patients with a long interval between last pain attack and diagnosis has stabilised. The second finding accords with current views and previous findings on the relevance of electrocardiography in such patients. ${ }^{1-31920}$

We did not attempt to relate the baseline risk of recurrent ischaemia or myocardial infarction within 48 hours to findings at subsequent coronary angiography. Unless there are compelling reasons for an emergency procedure, catheterisation is generally only carried out a few days after hospital admission at the earliest. Thus in most patients catheterisation results are not relevant to the initial management.

Does the clinical spectrum seen in the patients we studied in 1981-84 remain valid today? There does not seem to have been any major change in the initial clinical recognition of unstable angina and its differentiation from myocardial infarction or in the pharmacotherapeutic approach. On the other hand, emergency percutaneous transluminal coronary 
angioplasty or bypass surgery are now increasingly offered, with good results. ${ }^{21}$ It is unlikely, however, that the more general use of these procedures will have had any great effect on the clinical spectrum because such procedures are usually restricted to patients in whom chest pain persists despite maximal pharmacological treatment. In such cases angioplasty or bypass surgery may prevent the occurrence of myocardial infarction. Of the infarctions in the present trial only the later ones could have been prevented in this way, and there were only a few of these.

\section{EFFECTS OF TRIAL MEDICATION}

On the basis of an interim analysis enrolment in the present trial was discontinued (appendix I). This was because continuation of nifedipine monotherapy trial medication was considered to be unethical and, secondly, because there were only small differences between the other groups. The final data as presented here essentially accord with the interim data that led to this decision (tables 4 and 5 , and appendix I).

Although the series is large, the trial medication groups are rather small. In a randomised trial with small groups the results may indicate differences in the baseline risk between the groups. Table 2 shows that this was indeed the case. We used an approach developed for non-experimental epidemiological studies $^{22}$ to impose risk stratification based on a composite logistic function of relevant baseline characteristics on our study group and we have expressed trial medication effects as weighted averages of stratum specific rate ratios. This approach ensures that the estimation of trial medication effect becomes independent of the distribution of baseline risk in the groups that are compared. The use of $95 \%$ confidence intervals for the rate ratios so obtained provides a better indication of the statistical strength of evidence than the customary significance levels ( $p$ values). ${ }^{23}$

Patients with a pre-randomisation myocardial infarction are no longer at risk of the defined outcome events. Therefore, we excluded these patients before we assessed the trial medication effects. To allow for effect analyses based on other principles the number of pre-randomisation infarctions is also given per treatment group (table 4).

Of all the treatments studied only the addition of nifedipine to previous maintenance treatment with a $\beta$ blocker was clearly beneficial. None of the other trial regimens came out as being unequivocally effective. Furthermore, there was a worrying trend towards an increased risk for myocardial infarction in patients assigned to nifedipine alone. What is the explanation for these findings?
We postulate that when nifedipine is given to patients whose condition has become unstable despite maintenance treatment with a $\beta$ blocker coronary spasm may play a larger role than it does in patients not on $\beta$ blockade. This would explain the efficacy of additional treatment with a coronary spasmolytic agent such as nifedipine.

We do not believe that the apparent lack of effect of the other trial medications is caused by the selection of already stabilised patients, which would lead to too few potential outcome events. The event rate of recurrent ischaemia or myocardial infarction within $\mathbf{4 8}$ hours was considerable and accorded with the a priori design assumptions. Nevertheless, the confidence intervals given in table five do not exclude the possibility that relevant trial medication effects were missed. We believe that the most likely explanation lies in the particular clinical situation that this trial was designed to examine. The trial design assumed that neither ischaemia nor necrosis was present after eligibility had been established. We realised that because there are no specific early electrocardiographic signs of necrosis inclusion of some patients in whom myocardial infarction was already evolving would be unavoidable. Although we appreciated that enzyme concentrations increase within hours of the onset of myocardial infarction, we decided to exclude patients from trial medication assessment only if enzymes were already significantly raised at randomisation. This was decided for two reasons. Firstly, if enzyme measurements obtained after randomisation were used as a basis for exclusion the validity of comparisons between trial medications could be compromised. This would have occurred if any of the trial medications had affected the release of enzymes from necrotic myocardium rather than the amount of necrosis. Secondly, only enzyme measurements known at that time could be relevant to the formulation of treatment guidelines based on the results of this trial. Of patients classified as having recurrent ischaemia or myocardial infarction within 48 hours and retained in the analysis, a considerable proportion (92 out of 197 , table 1) sustained a myocardial infarction, generally before the start of trial medication or so soon thereafter that oral treatment could not be fully effective (fig 2). Thus an important fraction of the events on which effect estimation was based is unlikely to be affected by a preventive effect of trial medication, notwithstanding such an effect in another context. To be effective in this context a medication must not only prevent recurrent ischaemia or infarction in patients who are still at risk when treatment becomes effective but must also limit necrosis in those in whom the process of infarction has already progressed to the extent that 
an otherwise detectable infarction would become undetectable by current conventional diagnostic methods. Neither nifedipine nor metoprolol are likely to meet these requirements. Nifedipine has not been shown to reduce infarct size when given to patients with myocardial infarction. ${ }^{24}$ Animal experiments indicate that nifedipine does not protect the myocardium when given after onset of ischaemia. ${ }^{25}$ Nor is the effect of $\beta$ blockade on infarct size definitively known.

The reason why nifedipine monotherapy increases the risk of progression to myocardial infarction cannot be determined from our data. The nifedipine results may be a chance finding. On the other hand, they virtually exclude a major preventive effect of nifedipine used in this way for this indication. We do not believe that nifedipine's postulated influence on the release of enzymes ${ }^{26}$ explains this finding - there were more $Q$ wave infarcts in the nifedipine monotherapy group than in the placebo group (table 4). Relative to placebo, nifedipine did not raise the heart rate substantially but it reduced blood pressure. It is possible therefore that the temporary rise in heart rate in combination with a decrease in blood pressure, which has been observed before, ${ }^{27}$ plays a role.

Nifedipine is generally accepted to be of particular value in patients with ST elevation during pain. A hundred and one patients had these features before entry (table 1). Subgroup analysis did not show that these patients especially benefited from nifedipine alone.

COMPARISON WITH OTHER STUDIES

In another trial for which patients were selected at hospital admission treatment with four $20 \mathrm{mg}$ doses of nifedipine given over 24 hours was compared with placebo. ${ }^{28}$ Eligibility for the trial, however, required more prolonged chest pain than in the present trial and patients with electrocardiographic evidence of acute infarction were not excluded. Patients were later stratified into either acute or threatened myocardial infarction groups on the basis of the presence or absence of increased enzyme concentrations and $Q$ waves at randomisation. The group with threatened myocardial infarction resembled the patients that we studied. The rate of progression to myocardial infarction, $75 \%$ after 24 hours, was much higher, however, probably because chest pain had been present for longer. The progression rate in the nifedipine and placebo groups was similar, as was enzymatic infarct size. The number of patients who were also treated with a $\beta$ blocker was not reported, so direct comparison with our results is impossible. In another trial in patients diagnosed as having "threatened infarction" treatment with propranolol was compared with conventional treatment. ${ }^{5}$ The effect of propranolol resembled that of metoprolol in the present trial.

Treatments in patients with unstable angina after enzyme concentrations were known to be normal have been studied in several trials with varying selection criteria. In one the addition of nifedipine to a standard regimen of propranolol and long acting nitrates reduced recurrent ischaemia during a three month follow up. ${ }^{29}$ Nifedipine without concomitant $\beta$ blockade was not studied. Another trial compared a conventional step-up regimen of long acting nitrates and propranolol with increasing dosages of nifedipine during a treatment period of 14 days. ${ }^{30}$ Overall there were no differences in recurrent ischaemia and $14 \%$ progressed to infarction in both groups. Because this trial did not have a placebo control group it is not possible to tell whether both regimens were equally effective or equally ineffective. In the subgroup of patients who were on maintenance treatment with propranolol the addition of nifedipine controlled pain more rapidly than did the addition of nitrates o: an increase of the propranolol dose. On the other hand, in the subgroup of patients who were not on maintenance propranolol the administration of propranolol or nitrates or both controlled pain more rapidly than did nifedipine. Our results accord with these findings. Moreover, they provide evidence for a positive effect of a particular $\beta$ blocker in patients not already on such treatment compared with placebo and for a similar effect of nifedipine in patients already using a $\beta$ blocker.

\section{CLINICAL IMPLICATIONS}

The present results confirm that with currently available diagnostic methods it is impossible to reliably differentiate unstable angina from evolving myocardial infarction at admission of a patient to a coronary care unit. Many of the patients with suspected unstable angina have already sustained a myocardial infarction or are in the process of doing so.

Initial management must take into account the possible presence of evolving myocardial infarction. The first management objective therefore becomes the reduction of the total number of infarcts eventually diagnosed among this subgroup of patients, irrespective of the precise time of onset relative to the start of treatment. To achieve this treatment must both reduce the size of evolving infarctions and prevent those which are about to develop.

Our results indicate that previous use of a $\beta$ blocker is an important consideration. They suggest that in patients not already on a $\beta$ blocker, a $\beta$ blocker is the treatment of first choice. The fixed combination of metoprolol and nifedipine had no additional 
advantages. Patients with ST elevations during pain did not seem to benefit from nifedipine. Furthermore, nifedipine cannot be recommended as monotherapy because it was associated with a higher incidence of myocardial infarction. On the other hand, patients whose condition has become unstable despite maintenance treatment with a $\beta$ blocker can be expected to react favourably to the addition of nifedipine to a regimen of continued $\beta$ blockade.

We acknowledge with gratitude the leadership of the late Dirk Durrer, past chairman of the Executive Committee.

\section{Appendix I}

On 27 October 1984 the Policy Advisory Board was presented with the following interim classification results of 593 randomised patients who were included irrespective of protocol violations: line risk, a logistic function was fitted to the data. This function relates the probability of recurrent ischaemia or myocardial infarction within 48 hours to a set of baseline characteristics $\mathrm{X}_{1}, \mathrm{X}_{2}, \ldots, \mathrm{X}_{\mathrm{k}}$ using the logistic function:

$\left\{1+\exp \left[-\left(a+b_{1} X_{1}+b_{2} X_{2}+\ldots+b_{k} X_{k}\right)\right]\right\}^{-1}$.

CODING OF BASELINE CHARACTERISTICS

As a general principle only indicator variables were used-that is variables that assume the value 1 if the property at issue is present and 0 if otherwise.

ST depression and ST elevation (measured 0.08 seconds after the J point) was scored according to the following categories: absent; $<0.5 \mathrm{~mm}$; between 0.5 and $1.0 \mathrm{~mm}$; between 1.0 and $2.0 \mathrm{~mm}$; between 2.0 and $5.0 \mathrm{~mm} ;>5 \mathrm{~mm}$. Maximum values were recorded for the following groups of leads: (1) V2; (2) V3-V5; (3) II, III, aVF; (4) I, aVL, V6. Electrocardiographic characteristics were expressed in

\begin{tabular}{|c|c|c|c|c|}
\hline & $M I_{0}$ & No $M I_{0}$ & $R I / M I_{48}$ & $M I_{48}$ \\
\hline $\begin{array}{l}\text { Placebo } \\
\text { Nifedipine } \\
\text { Metoprolol } \\
\text { Combination }\end{array}$ & $\begin{array}{c}\text { No previo } \\
7 \\
7 \\
6 \\
7\end{array}$ & $\begin{array}{l}\text { reatment w } \\
86 \\
95 \\
89 \\
88\end{array}$ & $\begin{array}{l}r \\
30(35 \%) \\
41(43 \%) \\
28(31 \%) \\
30(34 \%)\end{array}$ & $\begin{array}{l}12(14 \%) \\
26(27 \%) \\
17(19 \%) \\
16(18 \%)\end{array}$ \\
\hline $\begin{array}{l}\text { Placebo } \\
\text { Nifedipine }\end{array}$ & $\begin{array}{c}\text { On contin } \\
5 \\
3\end{array}$ & $\begin{array}{l}\text { reatment } \\
96 \\
104\end{array}$ & $\begin{array}{l}\text { 44 (46\%) } \\
35(34 \%)\end{array}$ & $\begin{array}{l}18(19 \%) \\
15(14 \%)\end{array}$ \\
\hline
\end{tabular}

$\mathrm{MI}_{0}$, pre-randomisation myocardial infarction; $\mathrm{RI} / \mathrm{MI}_{\mathbf{4 8}}$, recurrent ischaemia or myocardial infarction within 48 hours; $\mathrm{MI}_{48}$, myocardial infarction within 48 hours.

For myocardial infarction within 48 hours the nifedipine:placebo rate ratio was 2.0 with a $95 \%$ confidence interval $(1 \cdot 1,3.6)$. The Policy Advisory Board recommended discontinuation of the trial on ethical grounds because of the observed adverse effect in the group on nifedipine alone and because the effects in the other groups were smaller than expected and would have required a much larger trial for adequate statistical power.

This recommendation was accepted by the Executive Committee, which included the principal investigators of the participating centres.

Measures to discontinue inclusion were put into effect immediately.

\section{Appendix II}

The baseline risk for recurrent ischaemia or myocardial infarction within $\mathbf{4 8}$ hours is defined as the probability that recurrent ischaemia or myocardial infarction would occur within 48 hours given the patient's baseline characteristics and trial medication assignment to placebo. To estimate a patient's base- terms of abnormalities present on the baseline electrocardiogram and of changes in the pain electrocardiogram relative to the baseline electrocardiogram. We used separate codes to indicate that the baseline or the pain electrocardiogram was not available. The latter circumstance is of clinical relevance because this would occur if the patient had arrived at the hospital after chest pain had subsided.

\section{VARIABLE SELECTION}

We used data on all patients to fit the logistic function. Variables indicating the patient's trial medication and pre-treatment with a $\beta$ blocker were kept in the model all the time.

Baseline characteristics were selected for inclusion in the model on the basis of their overall (statistical) contribution to prediction and on medical plausibility. None of the characteristics related to the patient's history or medication before admission to hospital was selected. Only the interval since the last attack of chest pain and certain electrocardiographic characteristics proved to be predictive for recurrent ischaemia or myocardial infarction within $\mathbf{4 8}$ hours. 
Table 6 Indicator variables (with coefficients and standard errors) retained in the logistic function of the baseline risk for recurrent ischaemia or myocardial infarction within 48 hours

\begin{tabular}{lllr}
\hline Indicator & Coefficient & Standard error & Patients \\
\hline Pre-treatment with a $\beta$ blocker & 0.402 & 0.352 & 177 \\
Pain free interval < 1 hour & 1.228 & 0.290 & 133 \\
Pain free interval between 1-3 hours & 0.414 & 0.254 & 186 \\
Baseline ECG missing & 0.246 & 0.533 & 20 \\
ST depression $\geqslant 0.1 \mathrm{mV}$ on baseline ECG & 0.713 & 0.271 & 93 \\
Pain ECG absent & -0.460 & 0.304 & 203 \\
More ST depression during pain than at baseline & 0.558 & 0.258 & 159 \\
More ST elevation during pain than at baseline & 0.731 & 0.271 & 101 \\
Constant & -1.252 & 0.354 & 515 \\
\hline
\end{tabular}

ECG, electrocardiogram.

${ }^{\star}$ Number of patients in whom the property considered was present.

The baseline risk function was obtained by setting the variables representing the patient's actual trial medication to values representing treatment with placebo.

Table 6 shows the variables that were eventually retained in the model with their coefficients and standard errors.

\section{STRATIFIED ANALYSIS}

Patients were ranked on the basis of their calculated baseline risk and were subsequently divided into three strata of low, medium, and high risk. The cutoff points were chosen so that each stratum contained an equal number of patients in whom recurrent ischaemia or myocardial infarction within 48 hours had occurred. We calculated rate ratios as weighted averages of the stratum specific rate ratios for each trial medication comparison and for each variable of interest, ${ }^{31}$ and thus adjusted for variability of the baseline risk. Confidence limits were calculated accordingly.

\section{References}

1 Nattel S, Warnica JW, Ogilvie RI. Indications for admission to a coronary care unit in patients with unstable angina. Can Med Assoc f 1980;122:180-4.

2 Goldman L, Weinberg $M$, Weisberg $M$, et al. A computer-derived protocol to aid in the diagnosis of emergency room patients with acute chest pain. $N$ Engl f Med 1982;307:588-96.

3 Yusuf S, Pearson M, Sterry H, et al. The entry ECG in the early diagnosis and prognostic stratification of patients with suspected acute myocardial infarction. Eur Heart f 1984;5:690-6.

4 Fischl SJ, Herman MV, Gorlin R. The intermediate coronary syndrome. Clinical, angiographic and therapeutic aspects. $N$ Engl $\mathcal{F}$ Med 1973;288:1193-8.

5 Norris RM, Clarke ED, Sammel NL, Smith WH, Williams B. Protective effect of propranolol in threatened myocardial infarction. Lancet 1978;ii:907-9.

6 Antman E, Muller J, Goldberg S, et al. Nifedipine therapy for coronary-artery spasm. Experience in 127 patients. N Engl f Med 1980;302:1269-73.

7 Hugenholtz PG, Michels HR, Serruys PW, Brower RW. Nifedipine in the treatment of unstable angina, coronary spasm and myocardial ischemia. $A m \mathcal{F} \mathrm{Car}$ diol 1981;47:163-73.

8 Hugenholtz PG, Verdouw PD, de Jong JW, Serruys PW. Nifedipine for angina and acute myocardial ischemia. In: Opie LH, ed. Calcium antagonists and cardiovascular disease. New York: Raven Press, 1984:237-55.

9 Vanhoutte PM, Cohen RA. Calcium-entry blockers and cardiovascular disease. $A m \quad \mathcal{F}$ Cardiol 1983;52:99A-103A.

10 Schanzenbächer P, Göttfert G, Liebau G, Kochsiek K. Coronary hemodynamic and metabolic effects of nifedipine in patients with coronary artery disease treated with beta-blocking drugs. $\mathrm{Am} \mathcal{F}$ Cardiol 1985;55:33-6.

11 Robertson RM, Wood AJJ, Vaughn WK, Robertson D. Exacerbation of vasotonic angina pectoris by propranolol. Circulation 1982;65:281-5.

12 Kern MJ, Ganz P, Horowitz JD, et al. Potentiation of coronary vasoconstriction by beta-adrenergic blockade in patients with coronary artery disease. Circulation 1983;67:1178-85.

13 Warltier DC, Gross GJ, Brooks HL. Coronary stealinduced increase in myocardial infarct size after pharmacologic coronary vasodilation. Am $\mathcal{f}$ Cardiol 1980;46:83-90.

14 Opie LH, White DA. Adverse interaction between nifedipine and $\beta$-blockade. $\mathrm{Br} \mathrm{Med} \mathcal{F}$ 1980;281:1462.

15 Robson RH, Vishwanath MC. Nifedipine and betablockade as a cause of cardiac failure. $\mathrm{Br} \mathrm{Med} \mathcal{J}$ 1982;284:104.

16 Lubsen J, Hugenholtz PG. Acute myocardial ischaemia: what information can be expected in the near future from ongoing clinical trials with nifedipine? Eur Heart $\mathcal{f}$ 1983;4(suppl C):131-5.

17 Meng RC, Chapman DG. The power of chi square tests for contingency tables. $\mathcal{F} A m$ Statist Assoc 1966;61:965-75.

18 Conti CR, Brawley RK, Griffith LSC, et al. Unstable angina pectoris: morbidity and mortality in 57 consecutive patients evaluated angiographically. $A m \mathcal{F}$ Cardiol 1973;32:745-50. 
19 Gazes PC, Mobley EM, Faris HM, Duncan RC, Humphries GB. Pre-infarctional (unstable) anginaa prospective study-ten year follow up. Circulation 1973;48:331-7.

20 Brush JE, Brand DA, Acampora D, Chalmer B, Wackers FJ. Use of the initial electrocardiogram to predict in-hospital complications of acute myocardial infarction. N Engl f Med 1985;312:1137-41.

21 de Feyter PJ, Serruys PW, van den Brand M, et al. Emergency coronary angioplasty in refractory unstable angina. $N$ Engl f Med 1985;313:342-6.

22 Miettinen OS. Stratification by a multivariate confounder score. Am $\mathcal{F}$ Epidemiol 1976;104:609-20.

23 Pocock SJ. Current issues in the design and interpretation of clinical trials. $\mathrm{Br} \mathrm{Med} \mathcal{F}$ 1985;290:39-42.

24 Sirnes PA, Overskeid K, Pedersen TR, et al. Evolution of infarct size during the early use of nifedipine in patients with acute myocardial infarction: The Norwegian Nifedipine Multicenter Trial. Circulation 1984;70:638-44.

25 Nayler WG, Sturrock WJ, Dillon JS. Reperfusion of the ischaemic myocardium: do the $\mathrm{Ca}^{2+}$-antagonists help? In: Hugenholtz PG, Goldman BS, eds.
Unstable angina. Current concepts and management. Stuttgart and New York: Schattauer, 1985:187-97.

26 Loogna E, Sylven C, Groth T, Mogensen L. Complexity of enzyme release during acute myocardial infarction in a controlled study with early nifedipine treatment. Eur Heart $\mathcal{F}$ 1985;6:114-9.

27 Boden WE, Korr KS, Bough EW. Nifedipine-induced hypotension and myocardial ischemia in refractory angina pectoris. $\mathcal{F} A M A$ 1985;253:1131-5.

28 Muller JE, Morrison J, Stone $\mathrm{PH}$, et al. Nifedipine therapy for patients with threatened and acute myocardial infarction: a randomized, double-blind, placebo-controlled comparison. Circulation 1984;69: 740-7.

29 Gerstenblith G, Ouyang P, Achuff SC, et al. Nifedipine in unstable angina. A double-blind randomised trial. $N$ Engl f Med 1982;306:885-9.

30 Muller JE, Turi ZG, Pearle DL, et al. Nifedipine and conventional therapy for unstable angina pectoris: a randomized, double-blind comparison. Circulation 1984;69:728-39.

31 Miettinen O, Nurminen M. Comparative analysis of two rates. Stat in Med 1985;4:213-26. 